\title{
The Level of Creativity among Management Employees, Academic Staff and Artistes and Its Relationship with Gender, Practical Experience and Age
}

\author{
Nadia Hayel Al-Srour ${ }^{1}$, Alia Al-Oweidi ${ }^{2}$ \\ ${ }^{1}$ The University of Jordan, Amman, Jordan \\ ${ }^{2}$ The World Islamic Sciences and Education University, Amman, Jordan \\ Email: aliaart2001@yahoo.com
}

Received November $27^{\text {th }}, 2012$; revised December $30^{\text {th }}, 2012$; accepted January $30^{\text {th }}, 2013$

\begin{abstract}
The purpose of this study is to investigate the level of creativity among management employees, Academic staff and artistes and its relationship with gender, practical experience and age. The sample of the study consisted of (272) participants, (164) management employees, (18) Academic staff and (90) artists. The findings of the study showed that the highest performance on the creativity test was for academic staff followed by artists and finally employees. There were significant statistical differences for the level of creativity on the total sample attributed to gender in the favor of females. Furthermore, there were differences in the favor of the age category $(25-35)$. With regard to the years of experience the findings showed that the creativity level is higher for the employees with less than (10) years' experience.
\end{abstract}

Keywords: Creativity; Management Employees; Academic Staff; Artists

\section{Introduction}

With the entrance of the third millennium all businesses (scientific, educational, artistic and administrative) started to look into competitive advantage which is based in its first instance on the ability of workers to be innovative and creative. This led those organizations to develop its concepts and management styles to prepare the climate for employees to be creative within an interactive environment contributing in linking and transferring knowledge and gained accumulative experiences in order to develop creativity for the best of developing the society (Ageyev, 2008, 2010).

Torrance (1993) defined creativity as the invention or origination of any new thing (a product, solution, artwork, literary work, joke, etc.) that has value. "New" may refer to the individual creator or the society or domain within which novelty occurs. "Valuable", similarly, may be defined in a variety of ways.

Renewal had became the essence of creativity for any organizations including management employees, academic staff and employees. It is noted that workers in those fields are sensitive for the problems of performance in their jobs in Jordan, and this is linked to several factors, including deficiencies in the search for creative solutions to the problems they face in their work. In this context management scholars indicated that nowadays organizations face complicated conditions making their need for creativity is an urgent need, as managers have be careful on developing the capacity of employees to contribute to solving problems, and participation in decision-making, and the generation of new ideas and teamwork efforts in order to reach creativity in production. The importance of creativity in academic and administrative work or even artistic work merged from its complex nature which includes feeling the problem that needs thinking in order to find a suitable and creative solution (Proctor, 1991; Sheridan-Rabideau, 2010).

Levels of Creativity.

There are many levels of creativity, those are.

Creativity on the individual level: this means employees had creative and novel ways to develop their work through normal characteristics such as intelligence and giftedness or through gained skills such as problem solving; those characteristics and skills can be taught and developed while intelligence and giftedness may help in this process.

Creativity on the group level: as there are fixed groups collaborate with each other to apply ideas in order to change the group performance for the best.

Creativity on the organizations level: there are organizations with high performance norms where the work flow is ideal and creative through individual and group efforts.

Many studies had differentiated between two types of creativity on the originations level, those are.

Technical level: this level is related to products and services and the production technology led by humans, this means the production of creative goods and services.

Administrative level: it is related to the organizational structure and the administrative process in the organization, and related indirectly to the basic activities of the organization (Noris, 1996).

Taylor divided creativity into three different levels, those are.

Expressive Creativity: where originality and competence are important.

Productive Creativity: related to the development of a machine, a product or a service.

Inventive Creativity: related to new methods.

Innovative Creativity: refers to the continuous development of ideas and resulting in new skills.

Emergence Creativity: This type rarely happens since it 
needs ideas and new and novel assumptions (Sternberg, 2000).

Many studies discuss creativity among management employees, academic staff members and artistes Al-Tal (2006) conducted a study to investigate the cognitive, emotional, social and physical characteristics of creative people in scientific, arts and literature fields in Jordan. Moreover, studying the differences in those characteristics according to the creativity field, gender, age and the economic level. The sample of the study consisted of (117) creative persons divided into two groups, the first older creative people and the second is the young ones. All members had awards on both national and international levels. The researcher administrated a questionnaire to achieve the aim of this study. The findings of the study showed that the sample members have a variety of characteristics mostly on those older ones who had cognitive characteristics followed by social ones then emotional ones and finally physical characteristics. With regard to the young creative people group the most apparent characteristics are social ones then cognitive, physical and finally emotional ones.

Also Al-Salmi (2008) studied the effect of practicing time management in developing administrative creative skills among secondary schools principals. The sample of the study consisted of (368) participants representing (20) supervisors, (48) principals and (300) teachers. The findings of the study showed that the agreement on principals' practice of time management was in a high level and the agreement degree on the availability of creative administrative skills was in a high level too.

Corpley (2003) conducted a study to investigate the personal creative characteristics among a group of scientists creative in physics and chemistry from one hand and a group of artists in the field of poetry, story and novels. The sample of the study consisted of (83) participants, (45) of them are male and female writers. The findings showed that there are significant statistical differences between scientists and writers in the favor of writers. Moreover, the results showed that there are significant statistical differences between males and females in the total degree of creativity.

Furthermore, Joseph (2003) investigates the creative characteristics of creative artists in the fields of music, drama and arts. The sample of the study consisted of (163) individuals. The findings of the study showed that the most important creative characteristics of the sample are the ambition for knowledge and searching for alternative solutions. Moreover, there were no significant statistical differences between males and females on the creative characteristics.

Dawson (2002) studied the characteristics of creative people in different fields. The sample of the study consisted of (285) male and female creators who achieve creative accomplishments and received awards in the field of medicine, sciences, computers, literature and arts. The findings of the study showed that there are common characteristics between the sample's members such as the ability to give attention, adventure, facing challenges and finding creative solutions.

Carpenter (2002) study aimed to investigate the most important emotional characteristics for Arts creative people and compare it with those in the literature field. The sample of the study consisted of (243) individuals. The findings of the study showed that the most important emotional characteristics are empathy, personality strength and honesty. Moreover, there were differences between both groups for the art group creators.

Moreover, Kanter (1982) conducted a study about the creative manager in the middle management in a sample of (165) managers in (5) organizations in order to determine the type of the managers who contribute in change and the common factors of any creative organization. The study concluded that creative and novel managers feel comfortable with change and creativity grows in the organization where specializations are integrated with a free flow of information. The characteristics felt by creators include feeling free with change within their view and clarity in direction as well as applying management with share through encouraging others to work as a team.

Khandaqji (2005) studied the relationship between using management information systems in Jordanian universities and administrative creativity in those universities. The findings showed that the level of administrative creativity in Jordanian universities is high except in strategic planning, administrative facilitation and encouraging creativity adoption. The findings showed there are significant statistical differences attributed to post variables in the favor of managers (unit manager, department manager).

Ramadan (1988) studied the determinants of the creative behavior in the Arabic academy for sciences, technology and marine transport. The findings showed that there are a positive strong relationship between the creative behavior and the demographic variables (leadership, administrative level, type of work climate, new ideas and training).

\section{Statement of Purpose}

Creativity is considered to be one of the most important factors in the professional and personal success of each individual. There is no doubt that managers in companies and organizations have their own effect on their employees since they are the model to be followed. If the manager showed creativity in his work this will be reflected on the performance of the employees. This is true for the academic staff who can drive their universities to success and even artists in the different artistic fields influence people through their production. Therefore, the current study is investigating the level of creativity among management employees, academic staff and artistes and its relationship with gender, practical experience and age.

\section{Study Importance}

The importance of this study is emerged from its aim of investigating creativity among an important and effective group in the society those are: management, academic staff and artists.

\section{Study Questions}

What is the level of creativity among management employees, academic staff and artists?

Are there any significant statistical differences between the level of creativity among management employees, academic staff and artists?

Are there any significant statistical differences between the level of creativity attributed to gender?

Are there any significant statistical differences between the level of creativity attributed to age?

Are there any significant statistical differences between the level of creativity attributed to years of experience?

\section{Definition of Terms}

Management employees: Departments mangers, section ma- 
nagers in public and private organizations in Jordan.

Academic staff: University teachers with Ph.D. degree in humanitarian and scientific majors working in Jordanian universities.

Artists: individuals with accomplishments in painting, acting, theater, sculpture and registered in the Jordanian artists syndicate.

\section{Study Limitations}

Time Limitations: the study is administrated in 2011.

Place limitations: the study is administrated in Amman city.

\section{Procedures}

\section{Population}

The population of this study consisted of all management employees in Amman city, academic staff in Jordan University and artists from the Jordanian artists syndicate.

\section{Study Sample}

The sample of the study consisted of (272) individuals, (164) employees, (18) academic staff and (90) artists.

\section{Instrumentation}

Creativity practices scale was used in order to determine the creativity characteristics, the scale consists of (76) items, answers were (yes, No, not Sure).

\section{Results and Discussion}

What is the level of creativity among management employees, academic staff and artists?

To answer this questions means, Standard deviations and ANOVA were calculated to determine differences between groups.

Table 1 showed that there are significant statistical differences between the three groups. Moreover, findings showed that the highest means on the creativity scale was for faulty members totaling (91.61) followed by artists (90.46). Meanwhile, the lowest mean was for employees totaling (77.49). This can be attributed that academic staff are creative because they has high academic degrees and the nature of their work encourages creativity because of the opportunities of learning and acquiring more knowledge. Moreover, academic staff practice competition among each other leading them to be creative and they had many workshops and all this can make them creative people in their work. For employees, creativity is low due to the routine nature of their work so their performance will not be novel all times and they are restricted with many laws that may prevent their creativity.

Are there any significant statistical differences between the level of creativity attributed to gender?

Table 2 Showed that females are more creative than males this may be attributed to the nature of females as they are quieter and more committed in performance and those are important requirements to meet innovation

Are there any significant statistical differences between the level of creativity attributed to age?

Table 3 showed that the highest mean on the creative scale was for the age group first $(25$ - 35) and the level of performance was close between Category two and three, and this refers to the individuals at the beginning of their work exploring their creative ways as intrinsic motivation and the desire to work increases the level of creativity to work among individuals.

Table 4 showed the values of Pearson coefficient between the total degree on creativity scale with age and gender variable.

The findings indicated that there is a reverse relationship between creativity from one hand and both age and gender variables as the level of creativity is decreased with age

Table 1.

Means, standard deviations and ANOVA results.

\begin{tabular}{ccccc}
\hline Group & M & SD & F & Sig. \\
\hline Management & 77.40 & 15.21 & 21.10 & 0.00 \\
Artists & 90.46 & 17.71 & & \\
Faculty & 91.61 & 20.85 & & \\
Total & 82.68 & 17.66 & & \\
\hline
\end{tabular}

Table 2.

Means and standard deviations according to gender variable.

\begin{tabular}{ccc}
\hline Gender & M & SD \\
\hline Male & 81 & 17.35 \\
Female & 87 & 15.65 \\
\hline
\end{tabular}

Table 3.

Means and standard deviations according to age variable.

\begin{tabular}{ccccc}
\hline Age & M & SD & F & Sig. \\
\hline $25-35$ & 91.04 & 20.11 & 8.47 & 0.00 \\
$36-45$ & 79.67 & 15.62 & & \\
+45 & 80.25 & 16.71 & & \\
Total & 82.05 & 17.40 & & \\
\hline
\end{tabular}

Table 4.

Pearson coefficient results for the total degree of creativity with age and gender variables.

\begin{tabular}{cccc}
\hline Pearson coefficient & Total & Age & Experience \\
\hline Total degree & & & \\
Age & -0.19751 & & \\
Experience & -0.15417 & 0.804645 & \\
\hline
\end{tabular}

Table 5.

Means of performance according to experience variable.

\begin{tabular}{ccc}
\hline Experience & $\mathrm{M}$ & $\mathrm{SD}$ \\
\hline $1-10$ & 89.80 & 21.48 \\
$11-20$ & 80.98 & 12.75 \\
\hline
\end{tabular}


Table 6.

Tukey test results for post differences according to experience variable.

\begin{tabular}{cccc}
\hline Experience & $11-20$ & $21-30$ & +30 \\
\hline $1-10$ & $8.82^{*}$ & $9.30^{*}$ & $9.79^{*}$ \\
$11-20$ & & 0.48 & 0.97 \\
$21-30$ & & & 0.49 \\
\hline
\end{tabular}

increase and years of experience as individuals first start working with enthusiasm and motivation and by time those norms decreased due to the routine and other types of pressures and problems they face in the workplace.

Are there any significant statistical differences between the level of creativity attributed years of experience?

Table 5 It is noted that the highest mean was for the employees with $(1-10)$ years of experience. The mean of creativity is starting to decrease with the increase of the experience. However, differences were close to all groups and this may be due to the boring and routine environment in workplace with years spent in the job, and this will reduce the chance of creativity among employees.

As noted in Table 6 there are significant statistical differences in the favor of $(1-10)$ years of experience. This may be explained that employees in this category of experience are still in the beginning of their career and need to improve themselves. Moreover, the new employment systems required them to be creative to keep them in their jobs.

\section{Conclusion}

Preparing training workshops to develop creative skills among management employees.

Conducting more studies about creativity in Jordanian universities.

Considering creativity as a national goal providing all the abilities to develop creativity among individuals in all levels.

Encouraging creative academic staff through different incentives.

\section{REFERENCES}

Ageyev, V. (2008). Creative education as a method of "production" of a human being as subject of his own history. XXII World Congress of Philosophy, Seoul, 30 July-5August.

Ageyev, V. (2010). Creative education as a way of the organization of self-development. Saarbrucken: LAP Lambert Academic Publishing.

Alsalmi, F. (2008). Time management and its impact on the development of creativity administrative skills managers secondary school instruction in the Holy City. Mecca, Umm Al-Qura University.

Al-Tall, S. (2006). Cognitive and emotional characteristics, social and physical creators in the fields of science, literary and artistic works in Jordan. Amman: Amman Arab University for Graduate Studies.

Carpenter, M. (2002). Emotional characteristics of creative student. Journal of personality, 72, 348-360.

Corpley, J. (2003). A Comparison of creative personality type of scientists and writers. Creative Research Journal, 15, 303-310.

Dawson, V. (2002). Personality and creativity in artist, writers and scientists. Journal of Personality Assessment, 72, 532-551.

Harasis, O. (2004). Creative behavior among academic staff, parameters and constraints field study on the Jordanian private universities. Mafraq: Al Al-Bayt University.

Joseph, F. (2003). Characteristics of creative artists. Creative Research Journal, 15, 282-297.

Kanter, R. M. (1982). The middle manager as innovator. Harvard Business Review 60, 95-105.

Khandakja, M. (2005). The relationship between the use of management information systems and administrative innovation from the viewpoint of administrators in Jordanian universities. Amman: University of Jordan.

Norris, C. (1996). Developing creative leaders for empowered schools. National Forum of Educational Administration and Supervision Journal, 17, 57-65.

Proctor, R. A. (1991). The importance of creativity in the management field. British Journal of Management, 2, 223-230.

Ramadan, E. (1998). Determinate of innovation with an application on Arabic academy for science, technology and Martine transport. MBA Thesis, Alexandria: The Advanced Management Institute.

Sheridan-Rabideau, M. (2010). Creativity repositioned. Arts education policy review, handbook of creativity. Cambridge: Cambridge University Press.

Torrance, E. P. (1993). The nature of creativity as manifest testing. New York: Press Syndicate of the University of Cambridge. 